\title{
Determination of the Area of Energy-efficient Working Equipment Position and Effective Digging Radius of Hydraulic Excavators in Open-pit Mining
}

\section{Sergey Markov}

Kuzbass State Technical University: Kuzbasskij gosudarstvennyj tehniceskij universitet imeni T F Gorbaceva

\section{Maxim Tyulenev ( $\nabla$ tma.geolog@kuzstu.ru )}

Kuzbasskij gosudarstvennyj tehniceskij universitet https://orcid.org/0000-0002-0227-8837

\section{Research}

Keywords: energy efficiency, effective digging radius, energy-efficient position of working equipment, hydraulic excavators, open-pit mining

Posted Date: January 3rd, 2022

DOI: https://doi.org/10.21203/rs.3.rs-1134395/v1

License: (c) (i) This work is licensed under a Creative Commons Attribution 4.0 International License. Read Full License 


\title{
Determination of the area of energy-efficient working equipment position and effective digging radius of hydraulic excavators in open-pit mining
}

\author{
Sergey Markov ${ }^{1}$, Maxim Tyulenev ${ }^{2}$ \\ T.F. Gorbachev Kuzbass State Technical University, Kemerovo, Russian Federation \\ ${ }^{1}$ ORCID: 0000-0002-3209-0296; Scopus Author ID: 57193791816 \\ e-mail: markovso@kuzstu.ru \\ 2 ORCID: 0000-0002-0227-8837; Scopus Author ID: 35957295000 \\ e-mail: tma.geolog@kuzstu.ru (corresponding author)
}

\begin{abstract}
Since the end of the last century, a significant number of hydraulic excavators have arrived on Russian quarries. Most of these excavators are equipped with backhoe operating equipment. The widespread use of such excavators in open-pit mining proves their exceptional efficiency. However, at the same time there is no clear understanding of the conditions under which a hydraulic excavator will be most effective: a theory of the face block of hydraulic shovels has not yet been developed. The available scientific studies are limited to determining the rational height of the excavation layer for efficient operation. If to take the quality of preparation of rock mass and the scheme of its loading into dump trucks as external parameters, i.e. not depending on the features of excavator design, then the position of its working equipment relative to the rock block has a decisive influence on operation of the hydraulic drive and fuel consumption. This is due to the changing value of digging force at various points of the bucket teeth position in the range of their possible positions at constant power of the hydraulic drive. Thus, application of optimal position of hydraulic excavator working equipment elements (bucket, arm, and boom) relative to the rotary platform and the rock massive during the digging cycle allows both to reduce fuel consumption and to increase the digging force. The application of the developed methodology is promising in terms of improving the energy efficiency of both individual excavation and loading units and the enterprise as a whole.
\end{abstract}

Keywords: energy efficiency, effective digging radius, energy-efficient position of working equipment, hydraulic excavators, open-pit mining

\section{Introduction}

Currently, there is a tendency at open-pit coal mines to increase the number of hydraulic excavators working on excavation and loading of overburden and coal. This explains the increased attention to determining the optimal parameters of equipment operation, ensuring minimum consumption of resources without loss of productivity. A number of papers are devoted to this issue, and the working process of excavators of different types has been studied. In particular, papers [1-3, $22,24]$ have been aimed at description of interaction between rocks and dragline bucket; the articles $[4,5,7]$ give the results of cutting ground with buckets of different equipment; works $[8,9,14]$ are aimed at modeling of ground digging, including modeling by discrete-element method. Separately, we should note the fundamental work on the theoretical foundations of loosening of soils, modeling of working processes and prediction of parameters of excavation machines [13]. Articles [15-18] describe modeling the dynamics of the digging process in terms of technology without taking into account the parameters of a particular face. The works $[10,19,20]$ are aimed at solving technological issues of hydraulic excavators' application.

As practice shows, the use of hydraulic shovels leads to a decrease in coal excavation losses in comparison with similar by productivity rope shovels in the same mining and geological conditions. Especially strong positive effect on the reduction of losses is shown when using hydraulic backhoes in tectonically disturbed zones with complex geological structure and in low thickness seams' mining $[21,22,26]$. In addition, the granulometric composition of the blasted rock mass excavated by hydraulic shovels, is favorable for its use for various purposes: arrangement of road pavement, preventing the premature wear of tires of open-pit dump trucks [27] and so on. The reason for this is more stringent requirements for drilling and blasting preparation of overburden rocks in comparison with rope excavators. In a number of works such problems as design of typical passports of faces, 
studying the influence of face type on excavator productivity and general indicators of their work, analysis of hydraulic excavators' operation in different conditions have been solved [19, 20, 23, 25]. In general, the rational conditions for the use of this type of excavation equipment are established and the reliability of its operation is evaluated [28]. However, there are practically no works devoted to determining the energy efficiency parameters of hydraulic excavators. The condition determining the position of the working equipment of hydraulic excavators, at which the maximum digging force is achieved at minimum pressures developed in the hydraulic system of the working equipment drive, is to achieve the maximum moments of force developed by the hydraulic cylinders of the bucket, arm and boom. Achieving this condition will ensure the minimum pressure developed by the hydraulic pump at the maximum power output, thus reducing the power consumption of its drive (diesel or electric) to a minimum and increasing the wear life of the working equipment elements joints, which is confirmed by the relevant studies $[6,11,12]$.

The effective power of the pumps for the hydraulic drive of the working equipment is generally calculated as the multiplication of the pressure developed by the pump, by the oil consumption rate. Part of the pressure is spent on movements of the working equipment, and part is spent on creating force on the cutting edge of the excavator bucket teeth. Minimizing pressure in the hydraulic system while maximizing digging force is a priority for energy efficiency because it minimizes the power consumption of the hydraulic pumps and therefore the power consumption of the excavator's power plant. It also reduces the negative impact of the increased pressure on the seals of the connections and the flexible hoses of the hydraulic drive.

\section{Materials \& Methods}

As an example, let's look at the kinematics of the Hitachi EX8000-6 hydraulic backhoe. Kinematic diagram is shown in Fig. 1.

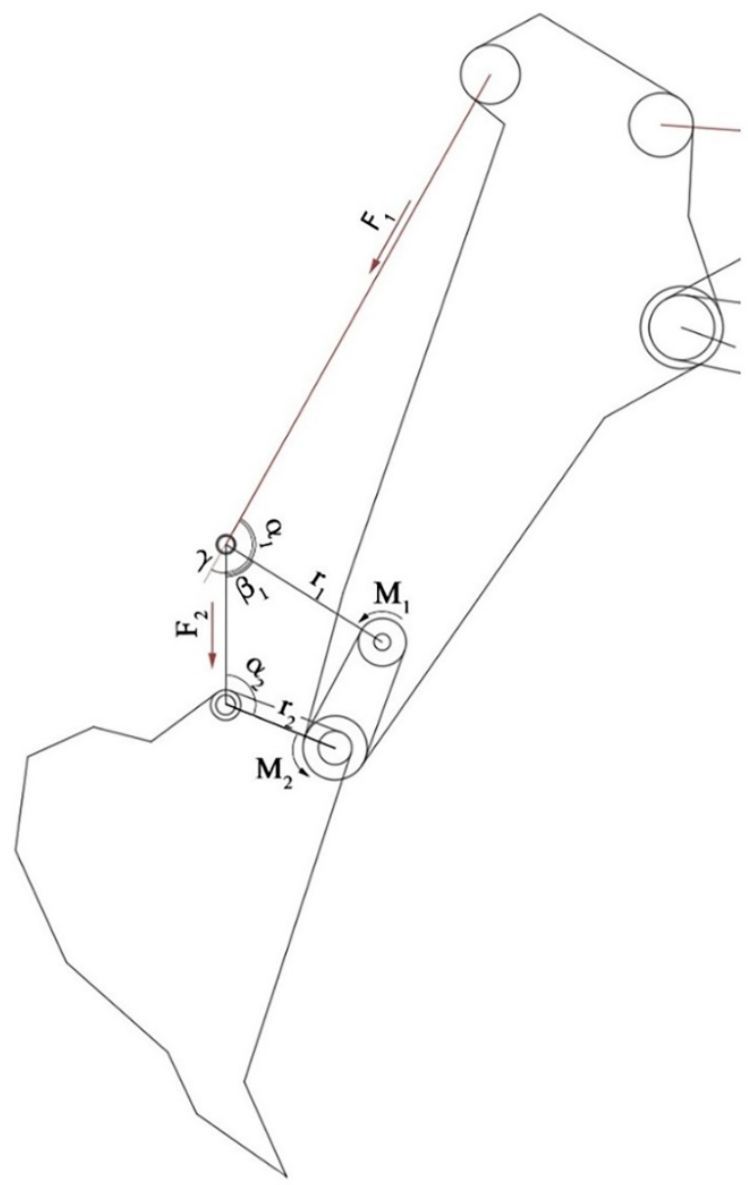

Fig. 1. Kinematic scheme of a backhoe bucket: $F_{1}$ is the force developed by the bucket hydraulic cylinder; $\alpha_{1}$ is the angle between the hydraulic cylinder rod and the first lever of length $r_{1} ; F_{2}$ is a part of the hydraulic cylinder force transmitted to the second lever, located at an angle $\beta_{1}$ to the first 
lever; $\alpha_{2}$ is the angle between the second lever and the line connecting the centers of the bucket eyelets.

The torque of the hydraulic cylinder force, which causes the bucket to turn, is equal to

$$
M_{2}=F_{2} \cdot \sin \alpha_{2} \cdot r_{2}
$$

In this case the torque $\mathrm{M}_{2}$ will take the maximum value at $\alpha_{2}=90^{\circ}$ and the maximum value of $\mathrm{F}_{2}=\mathrm{F}_{1}$ (i.e. at $\alpha_{1}+\beta_{1}=180^{\circ}$ or at $\gamma=0$ ). In general, the fulfillment of the condition of reaching the maximum torque for the bucket rotation

will look as follows:

$$
M_{2} \rightarrow \max
$$

$$
\left\{\begin{array}{l}
\left(\alpha_{1}+\beta_{1}\right) \rightarrow \pi \\
\alpha_{2} \rightarrow \frac{\pi}{2}
\end{array}\right.
$$

Implicit expression of the condition of reaching the maximum torque is due to the fact that the equipment manufacturer reserves the right to make changes in the design of individual elements (arms, buckets, etc.), including their dimensions. Thus, it is not possible to analytically accurately describe and calculate the bucket position relative to the arm, corresponding to the maximum torque of the hydraulic cylinder.

The graph-analytical method of solving (2) and (3) is the most acceptable for any component of the working equipment of the backhoe, installed at the current moment on the excavator. Its essence consists in modeling a turn of a bucket relative to an arm at extension of the hydraulic cylinder rod from minimal (retracted) to maximal (extended) position with simultaneous measurement of angles $\alpha_{1}, \alpha_{2}$, and $\beta_{1}$.

As the limiting position of the hydraulic cylinder and levers, at which the equality $\alpha_{1}+\beta_{1}=180^{\circ}$ is executed, is impossible owing to design features of the excavator working equipment, then, having expressed $F_{2}$ through $F_{1}$, it is possible to find an optimum position of elements of a drive of the bucket at which the moment $\mathrm{M}_{2}$ will be maximal:

$$
\begin{gathered}
F_{2}=F_{1} \cdot \cos \gamma, \\
\gamma=\pi-\left(\alpha_{1}+\beta_{1}\right), \\
M_{2}=F_{1} \cdot \cos \gamma \cdot \sin \alpha_{2} .
\end{gathered}
$$

The maximum length of the fully extended hydraulic cylinder of the Hitachi EX8000 6 excavator bucket drive is $7590 \mathrm{~mm}$, while the fully retracted one is $4690 \mathrm{~mm}$ (approximately). To find the maximum reduced torque $\mathrm{M}_{2}\left(\right.$ at $\mathrm{F}_{1}=1$ and $\left.\mathrm{r}_{2}=1\right)$ in the specified range of values with the step of $100 \mathrm{~mm}$ the movement of the hydraulic cylinder rod and the corresponding to its rotation of the bucket of the given excavator were simulated. The simulation results are shown in Table 1 and in Fig. 2, 3.

Table 1

Values of angles $\alpha_{2}$ and $\gamma$, length of the bucket drive cylinder $L$ and reduced torque $\mathrm{M}_{2}$ (with $\mathrm{F}_{1}=1$ and $\mathrm{r}_{2}=1$ )

\begin{tabular}{|c|c|c|c|}
\hline length of the bucket drive cylinder $\mathrm{L}, \mathrm{mm}$ & $\alpha_{2}$, degrees & $\gamma$, degrees & $M_{2}, \times 100 \mathrm{~N} / \mathrm{m}$ \\
\hline 5000.00 & 128.58 & 17.47 & 74.5679954 \\
\hline 5100.00 & 124.98 & 18.55 & 77.6783908 \\
\hline 5200.00 & 121.53 & 19.57 & 80.3127785 \\
\hline 5300.00 & 118.20 & 20.52 & 82.5384648 \\
\hline 5400.00 & 114.96 & 21.43 & 84.3924311 \\
\hline 5500.00 & 111.79 & 22.30 & 85.9104066 \\
\hline 5600.00 & 108.67 & 23.15 & 87.1093975 \\
\hline 5700.00 & 105.60 & 23.96 & 88.0166069 \\
\hline 5800.00 & 102.56 & 24.77 & 88.6267537 \\
\hline
\end{tabular}




\begin{tabular}{|c|c|c|c|}
\cline { 2 - 4 } 5900.00 & 99.54 & 25.56 & 88.965757 \\
\hline 6000.00 & 96.54 & 26.35 & 89.0268144 \\
\hline 6100.00 & 93.54 & 27.15 & 88.8117103 \\
\hline 6200.00 & 90.53 & 27.96 & 88.3237341 \\
\hline 6300.00 & 87.52 & 28.75 & 87.5905602 \\
\hline 6400.00 & 84.48 & 29.66 & 86.4947474 \\
\hline
\end{tabular}

The data presented in Table 1 show that the maximum torque occurs at bucket cylinder lengths from $5900 \mathrm{~mm}$ to $6100 \mathrm{~mm}$.

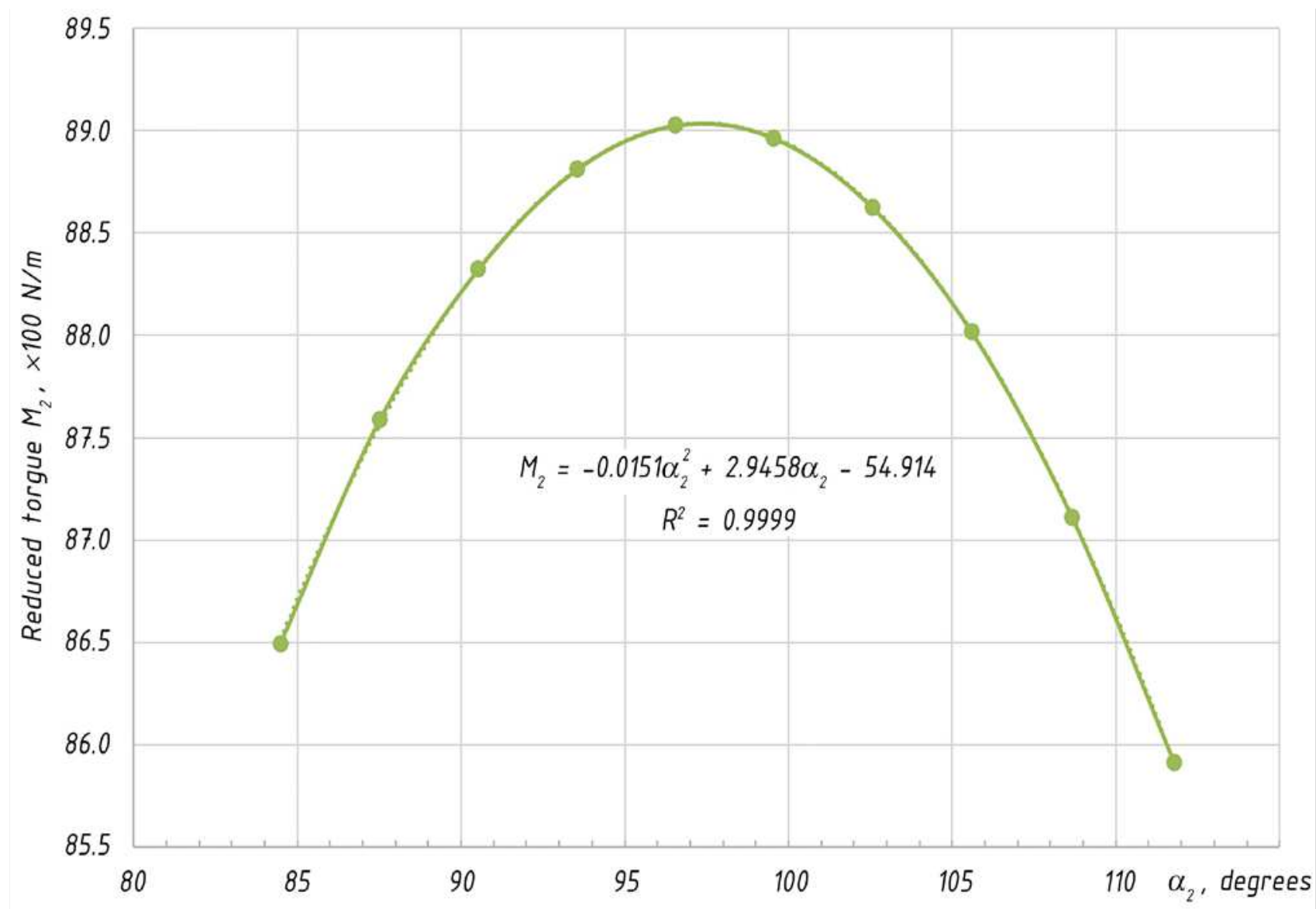

Fig. 2. Dependence of the reduced torque $\mathrm{M}_{2}$ on the angle $\alpha_{2}$

The resulting expression

$$
M_{2}=-0.0151 \cdot \alpha_{2}^{2}+2.9458 \cdot \alpha_{2}-54.414
$$

shows the qualitative dependence of the reduced torque $\mathrm{M}_{2}$ on the angle $\alpha_{2}$.

To find the angle $\alpha_{2}$ at the maximum torque $\mathrm{M}_{2}$, find the first derivative of the obtained dependence and solve it by equating it to zero:

$$
\begin{gathered}
M_{2}{ }^{\prime}=f^{\prime}\left(\alpha_{2}\right)=0, \\
-0.0302 \cdot \alpha_{2}+2.9458=0, \\
\alpha_{2}=97.54^{\circ}
\end{gathered}
$$

The maximum reduced torque is calculated by substituting the obtained value $\alpha_{2}$ into expression (5) and equals $8926 \mathrm{~N} / \mathrm{m}$.

A similar model can be applied to determine the length $L_{h}$ of the bucket hydraulic cylinder at the maximum reduced torque (Fig. 3): 


$$
\begin{gathered}
M_{2}^{\prime}=f^{\prime}\left(L_{h}\right)=0, \\
-0.0304 \cdot L_{h}+181.62=0, \\
L_{h}=5974.34 \mathrm{~mm}
\end{gathered}
$$

Thus, the bucket position in relation to the arm at bucket hydraulic cylinder length $L_{h}=5974.34$ $\mathrm{mm}$ or at angle $\alpha_{2}=97.54^{\circ}$ corresponds to the maximum torque $\mathrm{M}_{2}$, developed by the hydraulic cylinder of the Hitachi EX8000-6 backhoe.

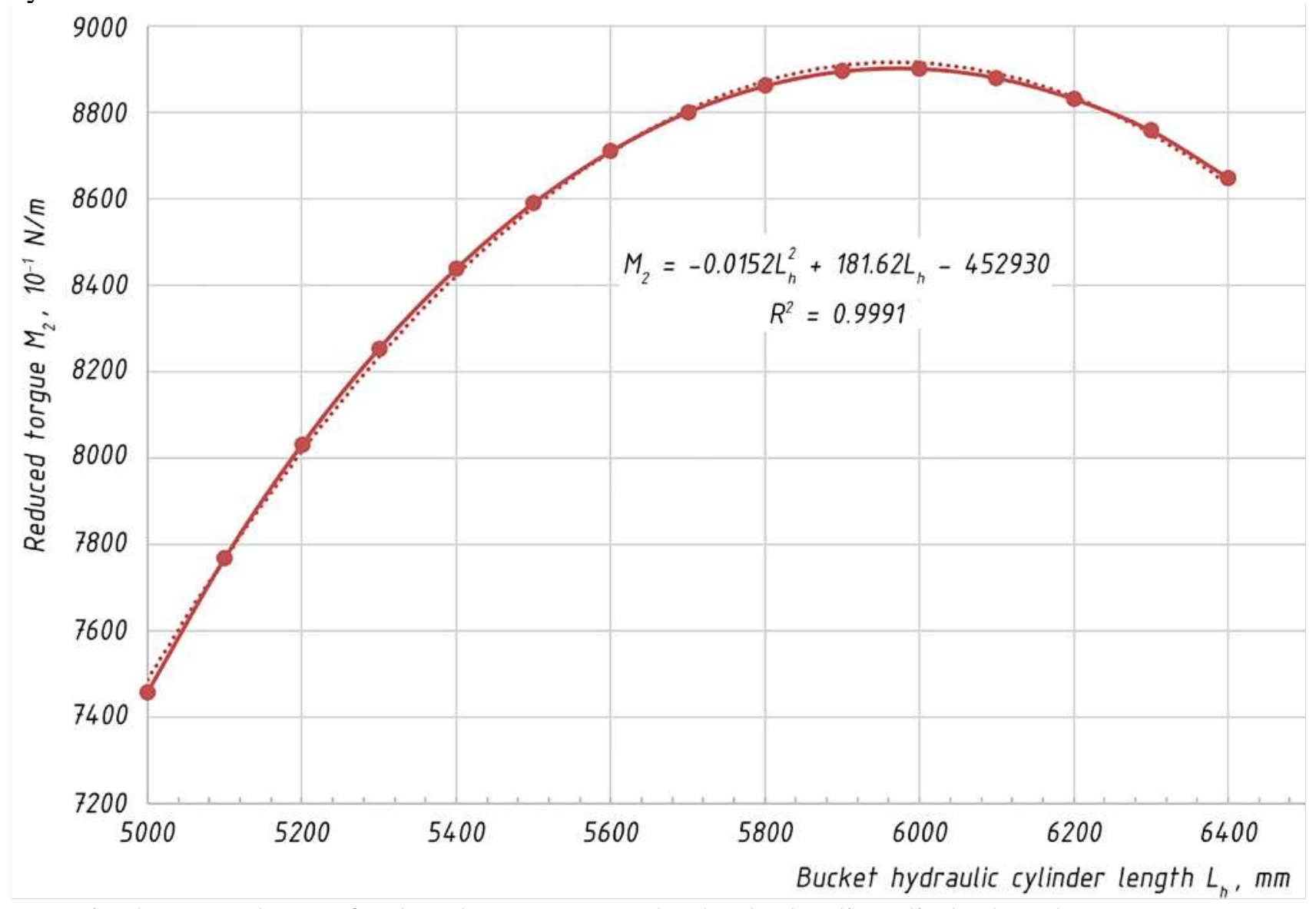

Fig. 3. Dependence of reduced torque $\mathrm{M}_{2}$ on bucket hydraulic cylinder length

Maximum energy-efficient condition of the "boom-arm" unit corresponds to such position of the arm at which its hydraulic cylinders develop the maximal torque (fig. 4). The kinematics of the arm is simulated graphically.

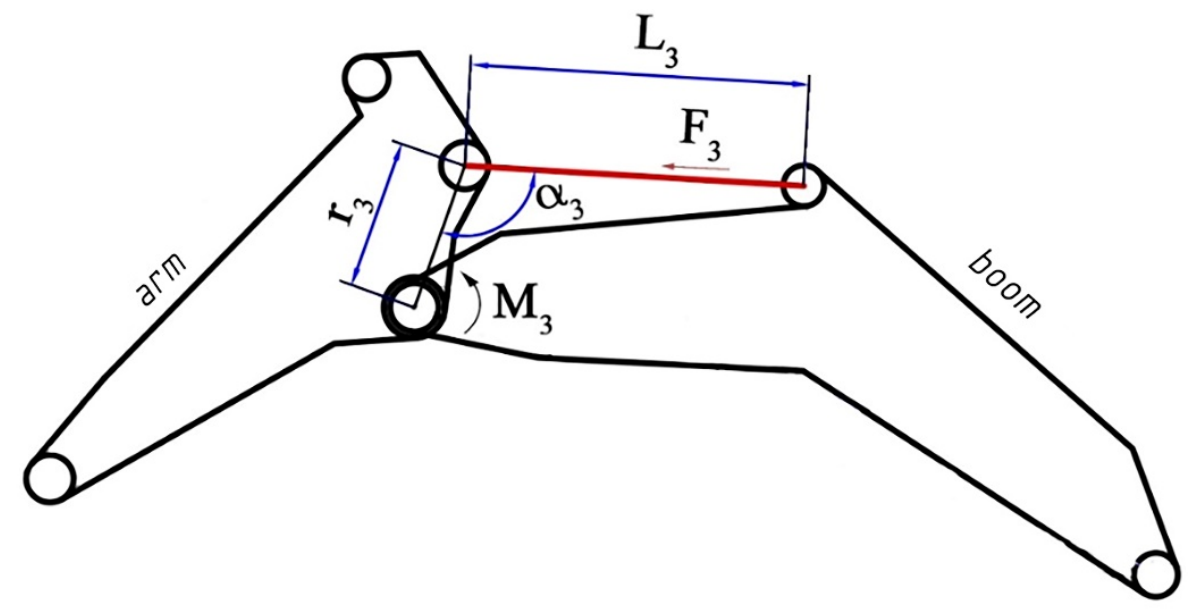

Fig. 4. Kinematic diagram of the backhoe arm: $F_{3}$ - force developed by the hydraulic cylinder of the arm; $r_{3}$ - lever that connects the axis of the hydraulic cylinder and the arm and the axis of the arm and the boom; $\alpha_{3}$ - angle between the hydraulic cylinder axis and the lever; $\mathrm{M}_{3}$ - torque of the arm, produced by the hydraulic cylinder. 
Based on the above diagram, the maximum torque of the arm occurs at an angle $\alpha_{3}=90^{\circ}$. The specified condition is fulfilled at hydraulic cylinder length $\mathrm{L}_{3}=5492 \mathrm{~mm}$.

It is more difficult to find the energy-efficient condition of the "boom - rotary platform" unit (Fig. 5). Value of the reduced torque $\mathrm{M}_{4}\left(\right.$ at $\mathrm{F}_{4}=1$ and $\left.\mathrm{r}_{4}=1\right)$ is found by the formula

$$
M_{4}=F_{4} \cdot \sin \alpha_{4} \cdot r_{4},
$$

where $\mathrm{F}_{4}$ is the force developed by the boom hydraulic cylinder; $\mathrm{r}_{4}$ is the lever connecting the mount axis of the hydraulic cylinder and the boom and the mount axis of the boom and the platform; $\alpha_{4}$ is the angle between the hydraulic cylinder axis and the lever.

The design features of the "hydraulic cylinder - boom - platform" system do not allow the angle $\alpha_{4}$ to reach $90^{\circ}$, so the maximum torque will be generated at the angle $\alpha_{4}$, which has the maximum value.

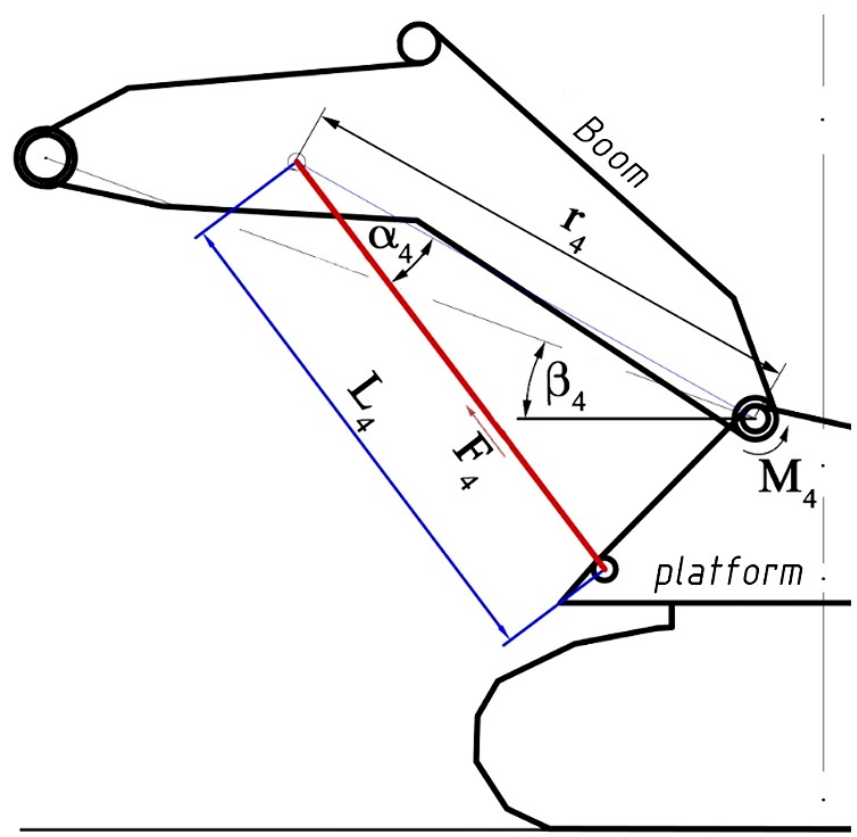

Fig. 5. Kinematic diagram of the backhoe boom: $F_{4}$ is the force developed by the boom hydraulic cylinder; $\mathrm{r}_{4}$ is the lever connecting the mount axis of the hydraulic cylinder and the boom and the mount axis of the boom and the platform; $\alpha_{4}$ is the angle between the hydraulic cylinder axis and the lever; $\mathrm{M}_{4}$ - the boom torque developed by the hydraulic cylinder; $L_{4}$ - hydraulic cylinder length (by the centers of the eyelets); $\beta_{4}-$ the boom tilt angle.

To find the boom position at which the angle $\alpha_{4}$ will reach the maximum value, the hydraulic cylinder rod movement and the corresponding rotation of the Hitachi EX8000 6 excavator boom were simulated. The results of the simulation are shown in Fig. 6.

To find the maximum value of the angle $\alpha_{4}$, let's find the solution of the first derivative of the obtained dependence, which is equal to zero:

$$
\begin{gathered}
\alpha_{4}^{\prime}=f^{\prime}\left(L_{4}\right)=0 \\
0.7371 \cdot L_{4}^{2}-13.102 \cdot L_{4}+56.126=0 \\
L_{4}=7.2 \mathrm{~m} .
\end{gathered}
$$

At this value of $L_{4}$, angle $\alpha_{4}=24^{\circ}$, angle $\beta_{4}=13.24^{\circ}$.

This position of the working equipment (boom, arm and bucket) of the Hitachi EX8000-6 backhoe is optimal in terms of effective use of the potential of this type of equipment. 


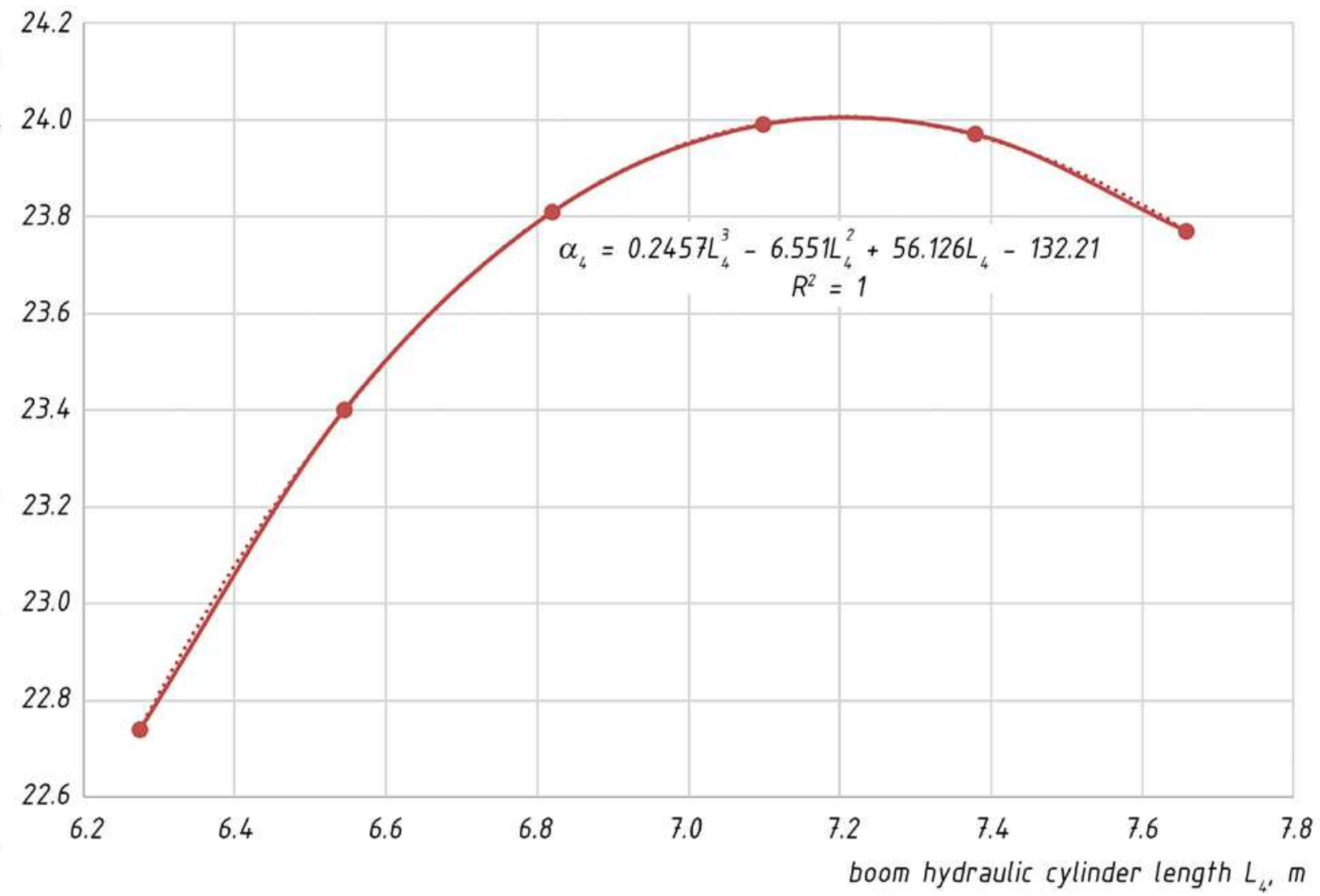

Fig. 6. Dependence of the angle $\alpha_{4}$ (between the hydraulic cylinder axis and the lever $\mathrm{r}_{4}$ ) on the boom hydraulic cylinder length $L 4$.

Mathematical model (1)-(9) describing optimum position of the working equipment can be used for calculations of any other equipment having similar design to that of Hitachi EX8000-6 backhoe.

\section{Results and discussion}

Application of the mathematical model (1)-(9) is not limited to finding the energy-efficient position of the working equipment. From the technological point of view, the use of the developed model makes it possible to find the part of the face relative to the excavator in which the energy consumption for rocks extraction will be minimal.

With this purpose it was simulated positions of boom, arm and backhoe bucket of Hitachi EX8000-6 at which angles $\alpha_{2}$ (see fig. 1), $\alpha_{3}$ (see fig. 4) and $\beta_{4}$ (see fig. 5) changed within the range of $\pm 5^{\circ}$ from their maximum effective values. Graphically the results of the simulation are shown in Fig. 7.

The outermost points of each segment shown in Fig. 7, correspond to the position of the bucket teeth when the angle $\alpha_{2}$ (see Fig. 1) deviates by $\pm 5^{\circ}$ from its most effective value. Horizontal groups of three segments correspond to the position of the arm when the angle $\alpha_{3}$ (see fig. 4) deviates by $\pm 5^{\circ}$ from its maximum effective value. The leftmost and rightmost limits of this area correspond to a deviation of the arm from its maximum effective position (change in angle $\beta 4$ in Fig. 5) by $+5^{\circ}$ and $-5^{\circ}$, respectively.

The most optimal position of the working equipment (energy-efficient position of the working equipment) of the excavator under consideration is achieved at the following values of hydraulic cylinder lengths and corresponding angles (see Fig. 1, 4, 5):

- bucket cylinder length $\mathrm{L}_{\text {buc }}=5974.34 \mathrm{~mm}$ or angle $\alpha_{2}=97.54^{\circ}$;

- arm cylinder length $\mathrm{L}_{\mathrm{arc}}=5492 \mathrm{~mm}$;

- boom cylinder length $\mathrm{L}_{b o c}=7200 \mathrm{~mm}$ or boom angle $\beta_{4}=13.24^{\circ}$. 


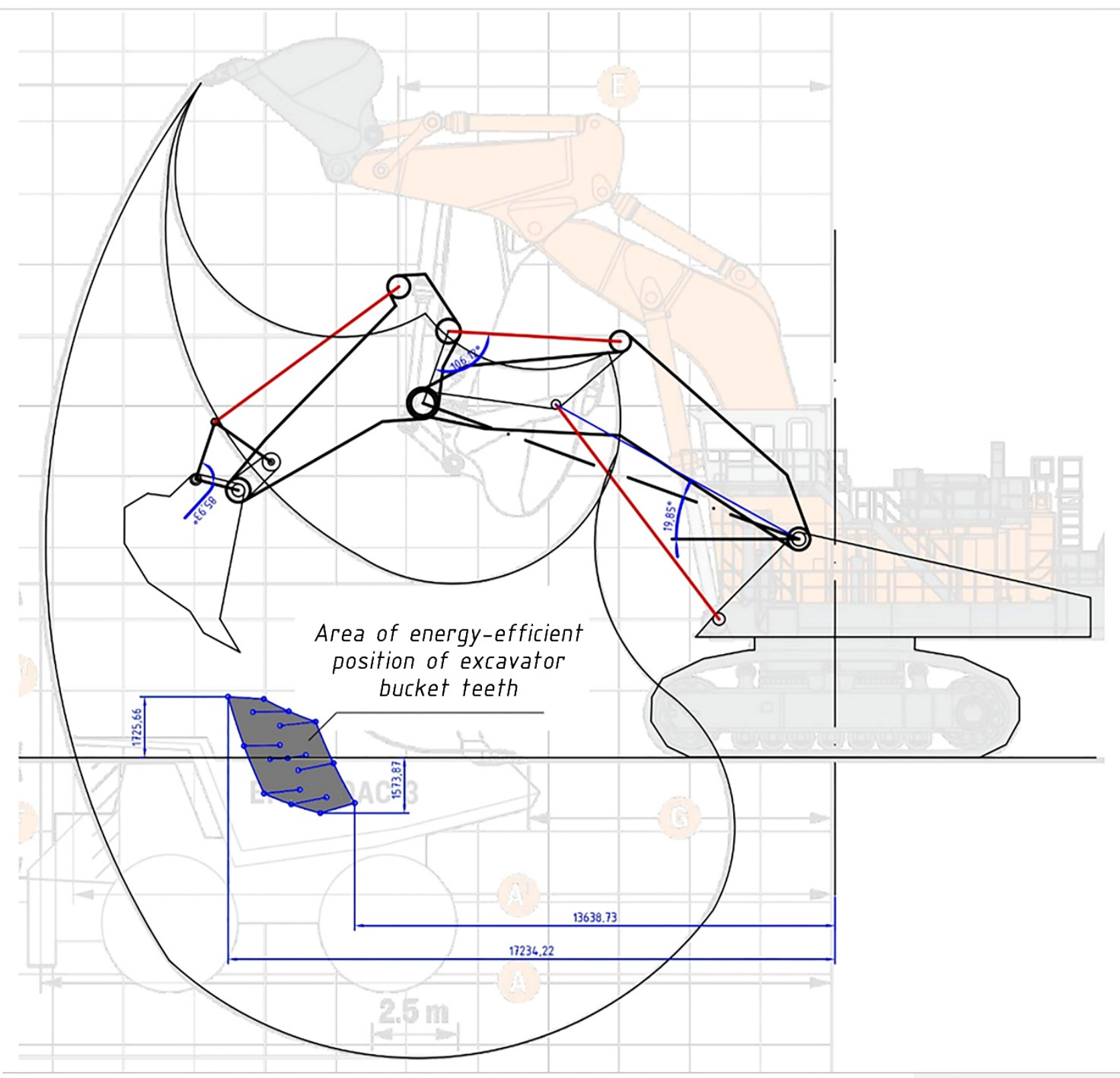

Fig. 7. Area of energy-efficient position of excavator bucket teeth relative to the maximum possible movement path of Hitachi EX8000-6 backhoe bucket

Analysis of the obtained results shows that the energy-efficient digging radius (EEDR) of Hitachi EX8000-6 backhoe changes in the range from $13.6 \mathrm{~m}$ to $17.2 \mathrm{~m}$; height (depth) of digging respectively from $+1.1 \mathrm{~m}$ to $-1.5 \mathrm{~m}$ relative to the excavator standing level. Thus, the area of energyefficient position of bucket teeth of the considered excavator is inside of the maximum possible trajectory of working equipment position (Fig. 7), and it is close enough from the geometrical center of the last. It is also remarkable that the central point of the area of the energy-efficient position of the excavator bucket teeth corresponding to the maximum effective position of the bucket, the arm and the boom, is at the excavator standing level (at a height of $\pm 0 \mathrm{~m}$ ) at EEDR distance, where it takes its most optimal value equal to $15.5 \mathrm{~m}$. However, the authors consider it necessary to clarify that this provision requires further testing and verification on excavator models of other manufacturers.

\section{Conclusion}

The method for determining the area of energy-efficient position of the working equipment of other brands and models of hydraulic excavators is similar: the maximum effective positions of each element of the working equipment are determined, then the parameters of the effective position of the 
working equipment as a whole are determined, and then the effective digging radius is calculated. This approach is applicable when calculating the optimal parameters of excavator position in the face. Application of the developed methodology will lead to reduction of operating costs and increase the productivity of excavation and loading equipment during mining operations.

\section{References}

1. Cleary P.W. The filling of dragline buckets // Math. Eng. Ind. 1998. Vol.7(1). P.1-24.

2. Dexter A.R. Soil physical quality. Part II. Friability, tillage, tilth and hard-setting // Geoderma. 2004. Vol.120. P.215-225.

3. Hettaratchi D.R.P. Modeling soil machine interaction // Proceedings of the 11th International Conference of the ISTVS, Lake Tahoe Nevada, USA, September 27-30. 1993.

4. Kushwaha R.L., Zhang Z.X. Evaluation of factors and current approaches related to computerized design of tillage tools: a review // J. Terramechanics. 1998. Vol.35. P.69-86.

5. McKyes E. Soil Cutting and Tillage. - The Netherlands, Amsterdam, Elsevier, 1985. - P. 217.

6. Frimpong S., Hu Y., Inyang $H$. Dynamic Modeling of Hydraulic Shovel Excavators for Geomaterials // International Journal of Geomechanics. 2008. Vol.8(1). P.20-29.

7. Gáspár F., Coţa C., Cârdei P., Viorel Fechete-Tutunaru L. Starting Traction Effort Evaluation for a Simple Tillage Tool // Annals of Faculty Engineering Hunedoara - International Journal of Engineering. 2019. Vol.12(2). P.51-54.

8. Obermayr M., Dressler K., Vrettos C., Eberhard P. Prediction of draft forces in cohesionless soil with the Discrete Element Method // Journal of Terramechanics. 2011. 48(5). P.347358. DOI: 10.1016/j.jterra.2011.08.003.

9. Patel B.P., Prajapati J.M. Evaluation of resistive force using principle of soil mechanics for mini hydraulic backhoe excavator // International Journal of Machine Learning and Computing. 2012. Vol.2(4). P.386.

10. Kolesnikov V.F., Cehlár M., Tyuleneva E.A. Overview of excavation and loading operations in the coal-bearing zones at Kuzbass open pit mines // Journal of Mining and Geotechnical Engineering. 2018. Vol.2. P.36-49. DOI: 10.26730/2618-7434-2018-2-36-49.

11. Rahman S., Chen $Y$. Laboratory investigation of cutting forces and soil disturbance resulting from different manure incorporation tools in a loamy sand soil // Soil and Tillage Research. 2001. Vol.58(1-2). P.19-29. DOI: 10.1016/S0167-1987(00)00181-1.

12. Singh S. Learning to predict resistive forces during robotic excavation. // Proceedings IEEE International Conference on Robotics and Automation. 1995. Vol.2. P.2102-2107. DOI: 10.1109/robot.1995.526025.

13. Zelenin A.N., Balovnev V.I., Kerov I.P. Machines for moving the earth: fundamentals of the theory of soil loosening, modeling of working processes and forecasting machine parameters // India, New Delhi, Amerind Publishing, 1985.

14. Awuah-Offei, K. Dynamic modeling of cable shovel formation interactions for efficient oil sands excavation: Ph.D. thesis / Univ. of Missouri-Rolla, Rolla, Mo.

15. Daneshmend L., Hendricks C., Wu S., Scoble M. Design of a mining shovel simulator // Innovative mine design for the 21st century, Baiden and Archibald eds., Kingston, Ont., Canada, 1993. P.551-561.

16. Frimpong S., Hu Y. Parametric simulation of shovel-oil sands interactions during excavation // Int. J. Surface Mining, Reclamation and Environment. 2004. Vol.18(3). P.205-219.

17. Koivo A.J., Thoma M., Kocaoglan E., Andrade-Cetto J. Modeling and control of excavator dynamics during digging operation // J. Aerosp. Eng. 1996. Vol.9(1). P.10-18.

18. Vaha P.K., Shibniewski M.J. Dynamic model of excavator // J. Aerosp. Eng. 1990. Vol.6(2). P.148-166.

19. Strelnikov A.V. Typical faces passports for the development of coal-bearing zones of Kuzbass quarry fields with backhoes. Part 1. General provisions // Journal of Mining and Geotechnical Engineering. 2019. Vol.3. P.4-20. DOI: 10.26730/2618-7434-2019-3-4-20. 
20. Strelnikov A.V. Typical faces passports for the development of coal-bearing zones of Kuzbass quarry fields with backhoes. Part 2. Passports of excavators faces // Journal of Mining and Geotechnical Engineering. 2019. Vol.4. P.4-29. DOI: 10.26730/2618-7434-2019-4-4-29.

21. Miliy S.M. Evaluation of technology for development of inclined and steep coal deposits in Kuzbass // Journal of Mining and Geotechnical Engineering. 2020. Vol.1. P.45-73. DOI: 10.26730/2618-7434-2020-1-45-73.

22. Vukotic I., Kecojevic V., Zhang W., Cai Q., and Chen S. 2013. Optimization of transport passage with dragline system in thick overburden open pit mine // International Journal of Mining Science and Technology. 2013. Vol. 23(6). P. 901-906.

23. Tyuleneva E.A., Lesin Yu.V., Litvin Ya.O. Research of the coal-bearing zones' mining technology at Kuzbass open pits using simple and complex faces // Journal of Mining and Geotechnical Engineering. 2019. Vol.1. P.35-49. DOI: 10.26730/2618-7434-2019-1-35-49.

24. Markov S., Janočko J., Tyulenev M., Litvin Y. Perspectives for the Transportless Mining Technology in Siberia and Far East Coal Deposits // E3S Web of Conferences. 2019. Vol.105. P.01021. DOI: https://doi.org/10.1051/e3sconf/201910501021.

25. Strelnikov A., Markov S., Rattmann L., Weber D. Theoretical Features of Rope Shovels and Hydraulic Backhoes Using at Open Pit Mines // E3S Web of Conferences. 2018. Vol.41. P.01003. DOI: https://doi.org/10.1051/e3sconf/20184101003.

26. Katsubin A., Markov S., Khoreshok A., Tyulenev M. Selection of Excavating Equipment for the Outpacing Development of the Coal-bearing Zone // E3S Web of Conferences. 2020. Vol.174. P.01027. DOI: https://doi.org/10.1051/e3sconf/202017401027.

27. Kvasova A., Gerike B., Murko E., Skudarnov D. Forecasting of a Thermal Condition of Pneumatic Tires of Dump Trucks // E3S Web of Conferences. 2017. Vol.21. P.03016. DOI: $10.1051 / \mathrm{e} 3$ sconf/20172103016.

28. Kolesnikov V., Litvin O., Janočko J., Efremenkov A. Using of Wide Stopes in Coalless Zones Mined by Shovels and Backhoes // E3S Web of Conferences. 2017. Vol.21. P.01031. DOI: 10.1051/e3sconf/20172101031. 